\title{
EFICACIA DE LAS ASOCIACIONES EMPRESARIALES PARA LA PARTICIPACIÓN DE LAS PYME EN EL NEGOCIO DE LA EXPORTACIÓN
}

\author{
Valiente Pantaleón Ramírez Huerta* \\ vramirezh@unms.edu.pe
}

\begin{abstract}
RESUMEN
Este estudio se propuso responder a la interrogante ¿qué formas de asociaciones empresariales son eficaces para la participación de las PYME en el negocio de la exportación? Los resultados arrojan que en Lima Metropolitana, entre el 2007 y 2011, se formaron 24 asociaciones con fines de exportación de las cuales 11 son consorcios, 13 franquicias, y ninguno a sub contratación, licencia de marca ni joint venture, por lo cual nuestra hipótesis "las asociaciones empresariales son eficaces para la participación de las PYME en el negocio de la exportación" se acepta. Se ha determinado que las más eficaces son las franquicias y consorcios, y los demás no son usuales. Los consorcios empresariales requieren acuerdos por consenso, mientras que las franquicias son más efectivas porque el trato directo entre el franquiciante y franquiciado es independiente en cada caso. Los resultados beneficiaran a las PYME para tomar decisiones apropiadas para lograr sus objetivos en cuanto a su participación en el comercio internacional a través de asociaciones empresariales, contribuyendo de esta manera al crecimiento económico y bienestar social del país.
\end{abstract}

Palabras claves: Asociación Empresarial, PYME, Exportación.

\section{ABSTRACT}

This study set out to answer the question what forms of business associations are effective participation of SMEs in the export business?. The results show that in Punjab between 2007 and 2011, 24 associations were formed for export of which 11 are consortia, 13 franchises, and none in sub contracting, licensing or joint venture brand. Therefore our hypothesis "business associations are effective participation of SMEs in the export business" is accepted. It has been determined that the most effective are franchises and consortia and others are unusual. Require business consortia agreements by consensus, while franchises are more effective because the direct relationship between the franchisor and franchisee is independent in each case. The results will benefit SMEs to make appropriate decisions to achieve their goals in terms of their participation in international trade through business associations, thereby contributing to economic growth and social welfare of the country.

Keywords: Business Association, SME, Export.

* Contador Público(UNASAM), Maestro en Ciencias Económicas con mención en Gestión Empresarial (UNASAM), Magister en Educación con Mención en Docencia en el Nivel Superior (UNMSM),Master Droit, Economie, GestionSpécialitéMangement International (UniversitéBordeaux 4 Montesquieu- Francia). Docente universitario y consultor de PYMES. 


\section{INTRODUCCIÓN}

En el contexto de la globalización económica, financiera, político, social, tecnológica, ambiental y cultural las empresas tienen que competir no solo con sus pares nacionales sino también con empresas del resto del mundo. Sin duda, se involucran en el comercio internacional ya sea directamente $\mathrm{o}$ indirectamente. Este trabajo busca evidenciar la experiencia de las PYME peruanas en relación a las asociaciones empresariales para exportar.

\section{Situación problemática}

Según la Organización de las Naciones Unidas para el Desarrollo Industrial (ONUDI) (2004: 3 y 4) establecer una presencia exitosa en mercados extranjeros es mucho más difícil que hacerlo en los mercados internos. Las PYME se ven disuadidas de exportar por lo complejo del negocio de exportación y los grandes riesgos que implica. Sin conocimientos y preparación significativos, los intentos de exportar están condenados al fracaso y pueden -incluso- poner en riesgo la estabilidad financiera de la empresa. Para desarrollar los mercados de exportación se necesitan conocimientos, esfuerzos y recursos financieros significativos. Los mercados extranjeros tienen sus particularidades y requisitos estrictos, no solo abarcan la demanda de los consumidores, sino además las obligaciones técnicas y regulatorias de los países receptores, identificar los mercados extranjeros apropiados, ponerse en contacto con los distribuidores locales y/o con los principales consumidores, aprender acerca de las preferencias de sus clientes, sin olvidar adaptar la calidad y el precio del producto. Los conocimientos especializados necesarios y el costo de hacer frente a esos problemas suelen superar la capacidad de las PYME consideradas individualmente.

Por ello, las PYME forman las asociaciones empresariales para la exportación, con el objetivo de vender sus productos (bienes y servicios) en el extranjero mediante acciones conjuntas. Las asociaciones constituyen un medio formal para la cooperación estratégica de mediano a largo plazo entre empresas.

De lo expuesto surgen las siguientes interrogantes: ¿qué formas de asociaciones empresariales son más efectivas para la exportación?, ¿qué formas de alianzas empresariales son eficaces respecto a los procedimientos complejos, altos riesgos, muchos recursos financieros, y normas técnicas?, ¿qué tipo de productos (bienes y servicios) peruanos se exportan más?, ¿cuáles son las formas de alianzas empresariales promovidas por el Estado?

\section{BASES TEÓRICAS}

\section{Comercio internacional}

Es el intercambio de productos (bienes y servicios) entre un sujeto domiciliado y otro no domiciliado, independientemente del lugar donde ocurra.

a) Razones por las que los países participan en el comercio internacional:

a) Diversidad de las condiciones de producción.

b) Diferencia de gustos de los consumidores.

c) Existencia de economías de escala por la producción en masa.

b) Ganancias en el comercio internacional

Según Krugman, Obstfeld y Melitz (2012: 3 y 4), cuando los países se venden mutuamente bienes y servicios se produce, casi siempre un beneficio mutuo, pese a las diferencias tecnológicas y salariales. El comercio internacional es beneficioso al permitir a los países exportar bienes cuya producción se realiza con una relativa intensidad de recursos que son abundantes en el país, mientras que importa aquellos bienes cuya producción requiere un uso intensivo de recursos relativamente escasos en el país.

c) Teorías del comercio internacional

- Ventajas Absolutas.- Smith (1776) dice que el libre comercio es la vía para la división internacional del trabajo. El productor que necesita una menor cantidad de insumos para producir un bien, tiene una ventaja absoluta en la producción de ese bien.

- Ventajas Comparativas.- Ricardo (1997) El productor que tiene el menor costo de oportunidad de producir un bien, tiene una ventaja comparativa en la producción de ese bien.

- Ventajas Competitivas.- Según Weinberger (2009) es aquella fortaleza que la empresa tiene para generar más valor para sus clientes y que no se puede imitar, resulta muy costoso hacerlo y es perdurable en el tiempo. 
d) Complejidades del negocio de la exportación Exportar es la salida legal de mercancías nacionales o nacionalizadas a otro país, además de la prestación de servicios en el exterior.

- Procedimientos

» Información permanente del mercado meta

» Logística de distribución física internacional

» Gestión de calidad y de finanzas internacionales

- Riesgos.- son eventos posibles, inciertos, aleatorios, concretos, lícitos y fortuitos en el futuro, que ocasionan consecuencias negativas o daños al patrimonio empresarial. Los riesgos se enfrentan con pólizas de seguros, donde el asegurador por el pago de una prima, se obliga a indemnizar al asegurado o beneficiario por las consecuencias.

En el comercio internacional los riesgos son:

» Pérdidas o daños durante el traslado de las mercaderías desde un lugar en un país, a un lugar en otro país de destino.

» Falta de pago de precio de la mercancía exportada.

- Recursos financieros.- Para exportar se requiere dinero y las fuentes de financiamiento son: aporte de los socios, préstamo bancario, crédito directo, arrendamiento financiero y emisión de bonos.

- Normas técnicas rigurosas.- Se debe alcanzar los estándares técnicos internacionales de aseguramiento de la calidad de los productos.

\section{Asociaciones empresariales para exportar}

Las formas de asociación que pueden desarrollar las PYMES entre sí o con empresas de mayor tamaño con el objetivo de exportar son:

\section{a) Consorcio de Exportación}

Según ONUDI (2004) a una alianza voluntaria de empresas con el objetivo de promover los bienes y servicios de sus miembros en el extranjero, y de facilitar su exportación mediante acciones conjuntas.
Ventajas:

- Generación de economías de escala por las compras en volumen.

- Mayor poder de negociación con proveedores, acreedores y clientes.

- Extensión de la oferta exportable y la capacidad financiera.

- Posibilidad de desarrollar una marca propia conjunta.

- Llegar directamente a los consumidores finales.

- Reducción del riesgo al acceder a información de mercados.

Desventajas:

- Están condicionados al consenso, es una fuente de conflictos.

- Sacrificar objetivos individuales en pro del objetivo común.

- Necesidad de directivos calificados y éticos los que son escasos.

- Afán de aprovechamiento de algunos integrantes del grupo.

b) Sub contratación

Según Mathews (2009), "sub contratación o sub contrata, articula a grandes empresas con pequeñas empresas" Según Ghelfi (s.f.) subcontratación (offshoring) es cuando la empresa A cede, total o parcialmente, la responsabilidad de realizar una función que hasta entonces asumía la empresa $\mathrm{B}$, situada fuera de su país.

Ventajas para la PYME subcontratada:

- Contar con una demanda sostenida y menos estacional.

- Mejora la calidad de sus procesos al tener un cliente más exigente.

- Recibe prácticamente sin costo el know how.

- Ahorro de capital de trabajo en materiales $\mathrm{y}$ otros insumos.

Desventajas:

- Compleja gestión de los activos intangibles.

- Diversidad normativa sobre propiedad intelectual entre países. 
- Disputas por la titularidad de derechos de propiedad intelectual.

- Dificultades para resolver controversias por jurisdicción territorial.

c) Licencia de marca

Según García (2009) implica el uso de la licencia por parte de un tercero debidamente autorizado mediante un contrato, a cambio de una contraprestación económica.

Ventajas:

- Identificación fácil de los productos por la marca.

- Se reducen comparaciones de precios por parte de clientes.

- Diferenciarse de la competencia.

- Potenciar la demanda de productos.

Desventajas para las licenciadas:

- Dependencia de la marca.

- Menor rentabilidad por las regalías a pagar por uso de marca.

- Supeditada a los estándares de las marca.

d) Franquicia

Según Mathews (2009) Es una alianza estratégica en la que una empresa que tuvo éxito, formatea su modelo de negocio, en manuales de marketing, de administración, de operaciones, etc. y transmite ese conocimiento empaquetado (know how) a un tercero llamado franquiciado, a cambio del pago de derecho entrada y regalías periódicas.

Ventajas para el franquiciado:

- Se cuelga de una marca comercial reputada.

- Tiene asistencia y transferencia permanente de nuevos consejos.

- Facilita el acceso al financiamiento.

- Pertenencia a una cadena identificable por el consumidor.

Ventajas para el franquiciador:

- Minimización de riesgos, por la atomización de las inversiones.

- Simplificación de los procedimientos de administración del negocio.
- Reducción de los costos operativos por economía de escala.

- Óptimo retorno de la inversión en la publicidad y promoción.

- Tiene un socio que conoce bien el mercado

- Genera ingresos por enseñar lo que sabe y no invierte.

Desventajas para el franquiciador:

- Comparte beneficios del negocio, al pagar regalías

- No tiene acceso a la propiedad de la marca.

- Sometida a una supervisión y control permanente de su negocio.

- Incertidumbre en cuanto a la duración del contrato.

Desventajas para el franquiciador:

- Rentabilidad unitaria baja, es una parte de los ingresos del franquiciado.

- Dispersión y relativización del control y dominio de la franquicia.

- Estructuras sofisticadas para atender las necesidades del sistema.

- Ponerse al frente de un sistema con protagonistas heterogéneos.

e) Joint venture

Según Mathews (2009) son alianzas de coparticipación entre dos empresas complementarias, donde una tiene lo que le falta a la otra. Una pone el dinero, la tecnología, la marca comercial; la otra, los recursos naturales, la ubicación estratégica, o los costos de fabricación más bajos.

Según Ortega (2006) el contrato de joint venture internacional es muy utilizado por las PYME para exportar sus productos.

Ventajas:

- Acceso a capitales, tecnologías, conocimientos, patentes y marcas.

- Aumento del proceso productivo, generando empleo y divisas.

- Acceso al mercado internacional, a través del socio extranjero.

- Mejoramiento de la capacidad de gestión y cultura empresarial. 
- Mejoramiento de la capacidad de investigación y desarrollo.

Desventajas

- Pérdida de autonomía de control.

- Conflicto de intereses a la hora de tomar decisiones.

- Compartir los beneficios económicos.

\section{Marco Legal}

\section{Texto Único Ordenado (TUO) de la Ley MYPE (2008)}

Art. 18 Fomento de la asociatividad, clusters y cadenas de exportación.

Art. 20 Promoción de las exportaciones, crecimiento, diversificación.

\section{Reglamento del TUO de la Ley MYPE (2008)}

Art. 13 Fomento de la asociatividad, clusters y cadenas de exportación.

\section{MÉTODOS}

\section{Hipótesis}

Las distintas formas de asociaciones empresariales son eficaces para que las PYME peruanas participen en el negocio de la exportación.

Tipificación. Cuantitativo, aplicada, descriptivo - correlacional, no experimental.

Población. 24 asociaciones empresariales de PYMES para exportar de Lima.

Recolección de datos. Técnica del análisis documental; instrumentos; fichas; fuentes: documentos de difusión de las asociaciones empresariales, las páginas web del Ministerio de Comercio Exterior y Turismo (MINCETUR), Ministerio de la Producción (PRODUCE), Superación Nacional de Aduanas y de Administración Tributaria SUNAT, etc.

\section{RESULTADOS}

Cuadro N.ำ Empresas formales en el Perú según tamaño

\begin{tabular}{|l|c|c|c|c|c|c|c|c|}
\hline & \multicolumn{2}{|c|}{ Perú \% } & \multirow{2}{*}{ Variación } & \multicolumn{2}{|c|}{ Perú en cantidades } & Lima & \multirow{2}{*}{$\begin{array}{c}\text { Lima / } \\
\text { Perú }\end{array}$} & Lima \\
& 2007 & 2011 & & 2007 & 2011 & 2011 & & $\%$ \\
\hline Micro & $95,4 \%$ & $94,5 \%$ & $9 \%$ & 1.125 .000 & 1.221 .343 & 579.411 & $47,4 \%$ & $92,8 \%$ \\
\hline Pequeña & $3,9 \%$ & $4,7 \%$ & $33 \%$ & 46.000 & 61.171 & 37.890 & $61,9 \%$ & $6,1 \%$ \\
\hline Mediana & $0,3 \%$ & $0,3 \%$ & $20 \%$ & 3.023 & 3.631 & 2.433 & $67,0 \%$ & $0,4 \%$ \\
\hline Grande & $0,4 \%$ & $0,5 \%$ & $20 \%$ & 4.977 & 5.979 & 4.317 & $72,2 \%$ & $0,7 \%$ \\
\hline Total & $100 \%$ & $100 \%$ & $9,6 \%$ & 1.179 .000 & 1.292 .124 & 624.051 & $48,3 \%$ & $100 \%$ \\
\hline
\end{tabular}

Fuentes: SUNAT (2008) y Ministerio de la Producción (2011).

Las pequeñas empresas en el 2007 constituían el $3.90 \%$ (46 000) y en el 2011 pasaron a 4,73\% (61.171), incrementándose en 33\%. Las medianas empresas pasaron de $0,26 \%$ (3.023) en el 2007 a $0.28 \%$ (3. 631) en el 2011, incrementándose en $20,1 \%$. Al 2011 las pequeñas y medianas empresas formales representaron el 5,01\% (49.023).
El 48,30\% de las empresas formales del Perú domicilian en la Región Lima; el 72,20\% de las grandes, $67,01 \%$ de las medianas, $61,94 \%$ de pequeñas y $47,44 \%$ de las micro empresas. Del total de empresas formales domiciliadas en Lima las PYME representan el 6,46\%. (40.323). 


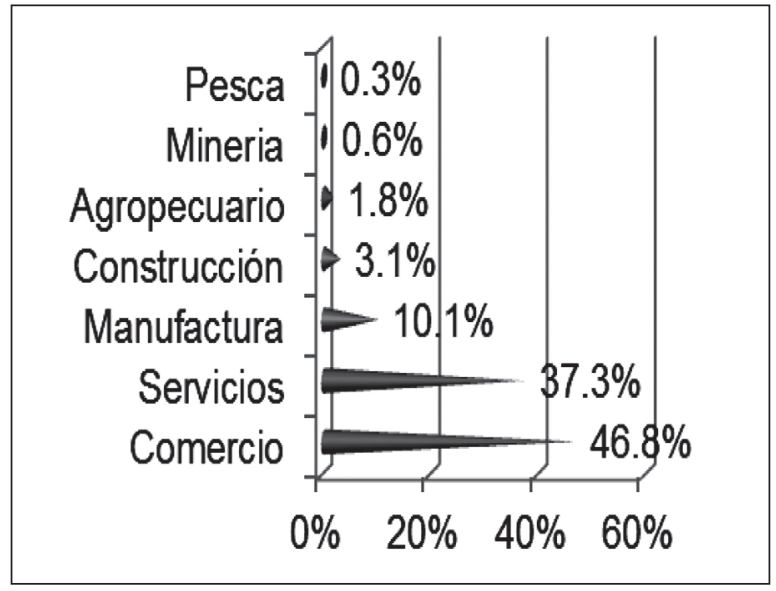

Fuente: Ministerio de la Producción

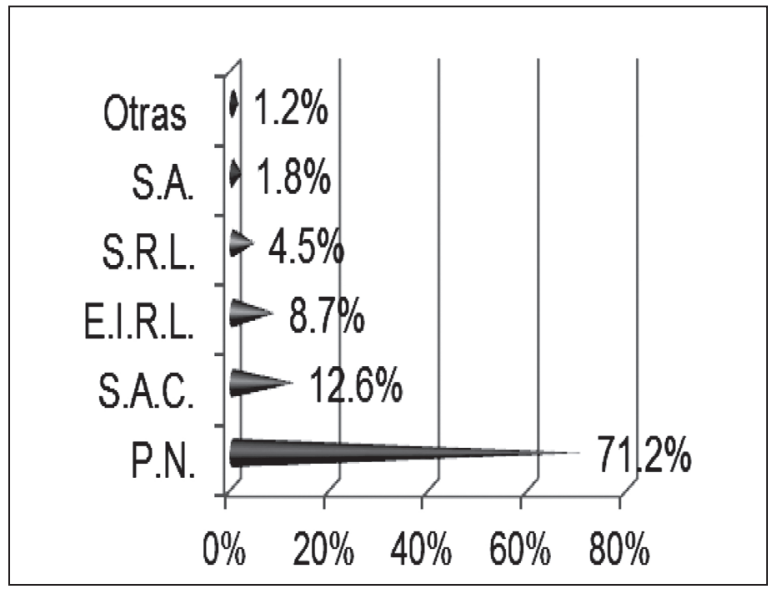

Fuente: Ministerio de la Producción

El 71,2\% de las empresas del Perú al 2011 pertenecen a un solo dueño, negocio unipersonal (PN.) y como Empresa Individual de Responsabilidad Limitada (EIRL) 8,66\%. Mientras que las formas societarias representan el 20,12\%, destaca la Sociedad Anónima Cerrada (SAC) con 12,61\%; la Sociedad Comercial de Responsabilidad Limitada (SRL) con 4,53\%. Según la actividad económica que desarrollan, el 46,82\% se dedica al comercio; el $37,32 \%$ a la prestación de servicios, actividades que concentran el $84,14 \%$ de la empresas. Solo el $10,09 \%$ se dedica a la industria y el $5,77 \%$ a las demás actividades.

\subsection{Asociaciones de PYME peruanas con fines de exportación}

Cuadro $\mathrm{N}^{\circ}{ }^{2}$ Consorcio para exportación

\begin{tabular}{|c|c|c|c|c|c|c|}
\hline \multirow[t]{2}{*}{$\mathbf{N}^{\mathbf{0}}$} & \multirow[t]{2}{*}{ Nombre } & \multirow[t]{2}{*}{ Consorciados } & \multicolumn{2}{|c|}{ Empleos } & \multirow[t]{2}{*}{ Mercado } & \multirow{2}{*}{$\begin{array}{c}\text { Oferta } \\
\text { Exportable }\end{array}$} \\
\hline & & & 2007 & 2011 & & \\
\hline \multirow[t]{3}{*}{1} & \multirow{3}{*}{ 돓 } & Laboratorios fitofarma EIRL & 37 & 11 & \multirow{3}{*}{$\begin{array}{l}\text { USA, } \\
\text { Europa, } \\
\text { Japón. }\end{array}$} & \multirow{3}{*}{$\begin{array}{l}\text { Ingredientes, } \\
\text { cosméticos y } \\
\text { suplementos } \\
\text { nutricionales }\end{array}$} \\
\hline & & Unifar - Eco siembra & 21 & $\mathrm{~S} / \mathrm{l}$ & & \\
\hline & & Peruvian Nature S\&S SAC & 27 & 41 & & \\
\hline \multirow[t]{4}{*}{2} & \multirow{4}{*}{ 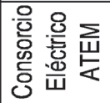 } & I\&T Electric SAC & 65 & 88 & \multirow{4}{*}{$\begin{array}{c}\text { Argentina, } \\
\text { Bolivia, } \\
\text { Ecuador, } \\
\text { USA }\end{array}$} & \multirow{4}{*}{$\begin{array}{c}\text { Ferretería de } \\
\text { transmisión, } \\
\text { aislamiento y } \\
\text { medición eléctrica }\end{array}$} \\
\hline & & Silicon Tec & 21 & 60 & & \\
\hline & & Procercool S.A. & 65 & 16 & & \\
\hline & & Javie & 1 & 0 & & \\
\hline \multirow[t]{4}{*}{3} & \multirow{4}{*}{ 를 } & Indu & \multirow{4}{*}{70} & 2 & \multirow{4}{*}{$\begin{array}{l}\text { Ecuador, } \\
\text { Bolivia }\end{array}$} & \multirow{4}{*}{$\begin{array}{l}\text { exhibidores, } \\
\text { refrigeradores, } \\
\text { freidoras, hornos y } \\
\text { mototaxis }\end{array}$} \\
\hline & & Inc & & 10 & & \\
\hline & & $\mathrm{CN}$ & & 4 & & \\
\hline & & $2 \mathrm{JJ}$ & & 1 & & \\
\hline \multirow[t]{4}{*}{4} & \multirow{4}{*}{ 넌 논 윽 } & Mc & 53 & 4 & \multirow{4}{*}{$\begin{array}{l}\text { Ecuador, } \\
\text { Bolivia }\end{array}$} & \multirow{4}{*}{$\begin{array}{c}\text { Casillas de metal, } \\
\text { muebles de metal } \\
\text { y accesorios para } \\
\text { cortinas }\end{array}$} \\
\hline & & Trim & 18 & 3 & & \\
\hline & & Inger & 15 & 4 & & \\
\hline & & DIM & 35 & 17 & & \\
\hline \multirow[t]{5}{*}{5} & \multirow{5}{*}{ 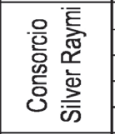 } & Jo & 13 & $\mathbf{0}$ & \multirow{5}{*}{$\begin{array}{l}\text { Venezuela, } \\
\text { Panamá, } \\
\text { USA }\end{array}$} & \multirow{5}{*}{$\begin{array}{l}\text { Joyeria de plata } \\
\text { con conchas } \\
\text { naturales y piedras } \\
\text { semi preciosas }\end{array}$} \\
\hline & & SAC & 15 & 0 & & \\
\hline & & Will & 10 & 1 & & \\
\hline & & Arte & 8 & $\mathrm{~S} / \mathrm{I}$ & & \\
\hline & & Mo & 9 & $\mathrm{~s}$ & & \\
\hline 6 & & Mor & 4 & $S / I$ & & \\
\hline & & & 9 & $\underline{S}$ & & \\
\hline & & as SAd & 9 & $\mathrm{~S} / \mathrm{I}$ & & \\
\hline & & Hugo $\mathrm{O}$. & 6 & 0 & & \\
\hline 7 & Peruviar & Jev & 2 & $\mathrm{~s}$ & & Joy \\
\hline 8 & Consorci & 0 & & & & \\
\hline 9 & Lendex c & 0 & & $\mathrm{~s}$ & & \\
\hline 10 & & Cre & & & & \\
\hline & 总 & & 110 & S & & damas caballeros \\
\hline & & & & & & y niños \\
\hline & & & & & & \\
\hline 11 & & Creaciones Lady Sandra EIRL & & 5 & & \\
\hline & & Creacion & 56 & 3 & & balleros \\
\hline & & $\mathrm{Cr}$ & & $\mathrm{S} / \mathrm{I}$ & & y niños \\
\hline & & Creaciones Shirley & & 1 & & \\
\hline
\end{tabular}

Fuente: ONUDI (2009), SUNAT y webs de consorcios. 
Los consorcios se constituyeron a finales del 2006 e inicios del 2007 generalmente como consorcios sin capital propio, agrupando a cuatro empresas, con el objetivo de promocionar sus productos en el mercado de Estados Unidos de América, Europa, Japón y Latino América, teniendo como potenciales clientes a los fabricantes y/o distribuidores de sus productos. En cuando a productos se aprecia una empresa de agroindustria, tres de metalmecánica, tres de joyería y cuatro de confección de ropas.

Sus logros en cada caso son:

- Desarrollo de una página web.
- Desarrollo del plan estratégico participativo o plan de negocios.

- Participación en ferias internacionales con apoyo del Estado.

- Incremento de las exportaciones de los miembros.

- Capacitación técnica y administrativa por parte de entidades del Estado.

- Participación en misiones comerciales con auspicio del Estado.

- Elaboración de material promocional impreso y electrónico.

Cuadro N. 3 Empresas de Franquicias Peruanas Internacionalizadas

\begin{tabular}{|c|c|c|c|c|c|c|c|c|}
\hline \multirow{2}{*}{$\mathbf{N}^{\circ}$} & \multirow{2}{*}{ Empresa } & \multirow{2}{*}{ Marca } & \multirow{2}{*}{ Producto } & \multirow{2}{*}{ CIIU } & \multirow{2}{*}{\begin{tabular}{|l|} 
Año \\
inicio \\
\end{tabular}} & \multicolumn{3}{|c|}{ Empleo Franquicias } \\
\hline & & & & & & 2011 & 2007 & 2011 \\
\hline 1 & Argentum Perú SAC & Thaya 925 & Joyas en plata & 39914 & 2006 & 12 & 0 & 1 \\
\hline 2 & Sabormania SAC & Mi propiedad privada & Cevichería & 55205 & 2002 & 24 & 0 & 1 \\
\hline \multirow[t]{3}{*}{3} & Cinco Millas SAC & Astrid y Gastòn & Restaurantes & 55205 & 1994 & \multirow{3}{*}{555} & 4 & 8 \\
\hline & & La Mar & Cevicheria & 55205 & 2005 & & 5 & 12 \\
\hline & & Tanta & Comida peruana & 55205 & 2003 & & 0 & 2 \\
\hline 4 & Alimentos San Charbel SAC & Heladería 4D & Heladería & 15499 & 1992 & 12 & 1 & 1 \\
\hline 5 & Bembos S.A.C. & Bembos & Amburguesa & 55205 & 1988 & 1758 & 2 & 4 \\
\hline 6 & Inversiones Kiyashi S.A. & Roky's & Pollos a la braza & 55205 & 1997 & 746 & 2 & 2 \\
\hline 7 & KERNFUSIE SAC & Osaka & Restaurantes & 55205 & 2002 & 39 & 0 & 2 \\
\hline 8 & Segundo Muelle SAC & Segundo muelle & Cevicheria & 74996 & 2000 & 8 & 3 & 4 \\
\hline 9 & $\begin{array}{l}\text { Servicios de Franquicias } \\
\text { Pardos's SAC }\end{array}$ & Pardo's Chicken & Restaurantes & 74145 & 1998 & 20 & 3 & 3 \\
\hline 10 & Grameco S.A.C. & Rosatel & Mensajería & 93098 & 1994 & 1 & 2 & 4 \\
\hline 11 & Alert del Perú S.A. & China Wok & Cómida rápida & 52206 & 1990 & 627 & 24 & 43 \\
\hline & Total & & & & & 3802 & 46 & 87 \\
\hline
\end{tabular}

Fuente: Promperú (S.F) y SUNAT

Existen empresas peruanas de franquicias, según el giro de negocio el 63\% (30) se dedican a la gastronomía, el $6 \%$ (3) comida rápida, $2 \%$ (1) cafetería, 6\% (3) juguería, 4\% (2) heladería, 2\% (1) artesanía, $2 \%$ (1) regalos, $2 \%$ (1) indumentaria, $4 \%$ (2) estética, 2\% (1) educación, 2\% (1) ferretería y $4 \%$ (2) joyería. De ellos han logrado internacionalizarse once que representa el $23 \%$, de los cuales el 55\% (6) se dedican a la gastronomía, $18 \%$ (2) comida rápida, 9\% (1) heladería, 9\% (1) regalos y $9 \%$ (1) joyería; y todas han sido constituidas como sociedad anónima.

En cuanto a marcas, diez empresas han desarrollado una cada uno, excepto Cinco Millas SAC. que desarrolló tres. Al 2011 la más antigua es
Bembos con 23 años, constituida a finales de la década del 80, seguida por seis empresas constituidas en la década de 90 , y cuatro empresas en la primera década de 2000. En menos de vente años la mayoría ha logrado posicionar su marca. Generaron en conjunto 3.802 empleos directos según lo declarado a la SUNAT.

Al 2007 se suscribieron cuarenta y seis 46 contratos de franquicias en el extranjero, mientras que al 2011 , fueron 87 , creciendo en $53 \%$ respecto al 2007. La empresa Alert del Perú SA., con su marca China Wok, suscribió el 50\% (43) de todos los contratos, seguida de Cinco Millas SAC. con sus marcas "La Mar" con doce (12) contratos, "Astrid \& Gastón”, con 8 y “Tanta”, con 2 que representa 
el $25 \%$, concentrando las dos empresas el $75 \%$ de las franquicias. Las restantes nueve empresas en conjunto representan el $25 \%$ de los contratos. Los países de destino según el número de empresas son Chile donde participan siete empresas, seguidos Ecuador, Panamá, España, México y Estados Unidos con cuatro 4 empresas en cada una; luego Colombia, Bolivia, Guatemala y Argentina con dos empresas, y el resto de países con una sola empresa de franquicias peruanas.

\section{DISCUSIÓN DE RESULTADOS}

Teóricamente se plantea que la exportación implica seguir procedimientos complejos, afrontar riesgos de pérdidas o daños al patrimonio, que implica financiar el pre y post embarque, también cumplir con los requerimientos técnicos de los mercados internacionales en cuanto a calidad y salubridad.

En la realidad encontramos que las PYME peruanas, a través de la asociación empresarial, logran afrontar con éxito tales exigencias. Mediante los consorcios de exportación se convierten en grandes empresas, incrementando su capacidad instalada, la oferta exportable, su capacidad de negociación con proveedores, clientes y acreedores. Por otra parte las franquicias peruanas son negocios exitosos en el Perú que han transferido su know how a diversos países del mundo a través de contratos que implican el pago de un monto por entrada y un porcentaje sobre las ventas mensuales por regalías.

Se ha determinado que el Estado, a través de Promperú y el Ministerio de Comercio Exterior y Turismo ha apoyado a las asociaciones empresariales como consorcios y franquicias con capacitación técnica y auspicio en la participación en ferias internacionales y misiones comerciales.

En cuanto a las actividades económicas que desarrollan encontramos una diversidad en los consorcios, pero en franquicias se concentran en su mayoría en la gastronomía peruana.

\section{Prueba de hipótesis}

De los resultados hemos podido evidenciar que los consorcios y las franquicias son eficaces para que las PYME peruanas exporten.

\section{CONCLUSIONES Y RECOMENDACIONES}

1. Las asociaciones empresariales son eficaces para la participación de las PYME en el negocio de la exportación. Los consorcios requieren acuerdos por consenso, se han creado promovidas por ONUDI y son temporales debido a los intereses heterogéneos de sus miembros. Las franquicias son más efectivas porque el trato entre las partes es independiente en cada caso, cada uno opera como un negocio independiente.

2. No se ha evidenciado que las PYME peruanas hayan celebrado contratos de licencia de marca, joint venture ni sub contratación para fines de exportación en el periodo de investigación.

3. Se debe promover la conformación de asociaciones empresariales para la participación de las PYME peruanas en las exportaciones a través del Consejo nacional Para el desarrollo de la Micro y Pequeña empresa (CODEMYPE), elaborando estrategias que incentiven a la PYME.

4. Se deben publicar estadísticas de asociaciones empresariales para exportar periódicamente así como los casos de éxito, a fin de tomar decisiones en base a los factores de éxito y así motivar a otras PYME.

\section{REFERENCIAS BIBLIOGRÁFICAS}

García Muñoz Nájar, Luis Alfonso. (2009). Propiedad intelectual - el uso de la marca como herramienta de mercado. USAID Perú, Lima.

Ghelfi, Donna. (s.f.). "La problemática de la 'subcontratación en el extranjero' desde la perspectiva de la propiedad intelectual". En: Organización Mundial de la Propiedad Intelectual (OMPI). (s.f.). Documentos. [En línea].Fecha de consulta: 29/11/2011. Disponible en: <www.wipo.int/sme/es/ documents/outsourcing.htm $>$.

Krugman, Paul R.; Obstfeld, Maurice y Melitz, Marc J. (2012). Economía internacional: teoría y política. Novena edición. Pearson, Madrid.

Mathews, Juan Carlos. (2009). Competitividad: el significado de competitividad y oportunidades de internacionalización para PYME. USAID y Ministerio de la Producción, Lima.

Ministerio de la Producción (PRODUCE ). (2012). Estadísticas MYPE 2011. Solvima Graf SAC. Lima 
Organización de las Naciones Unidas para el Desarrollo Industrial (ONUDI). (2008). Los Consorcios de Exportación dePYMES en el Perú.Informe técnicoproyecto ue/ glo/04/148promoción de consorcios de exportación[En línea].En:scribd fecha de consulta 30/11/2011. Disponible en: <http://es.scribd.com/doc/38951402/LosConsorcios-de-Exportacion-de-Pymes-enEl-Peru-ONUDI>

Organización de las Naciones Unidas para el Desarrollo Industrial (ONUDI). (2004). Guía de los consorcios de exportación. [En línea].ONUDI, Viena. Fecha de consulta:22/11/2011disponible en:http:// www.mincetur.gob.pe/comercio/ueperu/ consultora/docs_taller/Consorcios-ONUDI. pdf

Ortega Giménez, Alfonso. (2006). "El jointventure como forma de internacionalización”. [En línea].En:Centro para la Internacionalización de las Pymes (ExportaPymes). (s.f.). Comercio exterior América España, Noticias e información sobre internacionalización en Iberoamérica. Fecha de consulta: 02/12/2011. Disponible en: <http://www. exportapymes.com/comercio-exterioramerica-esp/el-joint-venture-como-formade-internacionalizacion/ $>$.

Promperú. (s.f.). Portafolio de franquicias internacionales Perú 2011. Promperú, Lima.

Ricardo, David. (1997). Principios de economía política y tributación. Fondo de CulturaEconómica, Santa Fé.
Smith, Adam. (1776). An Inquiry into the Nature and Causes of the Wealth of Nations. Londres, W. Strahan\& T. Cadell.

Superintendencia Nacional de Aduanas y de Administración Tributaria (SUNAT). (2008). Normas referidas a libros y registrosvinculados a asuntos tributarios R.S. 234-2006/ SUNAT. Material de dicertación en seminario desarrollado en 23/10/2008 en la Cámara de Comercio Industria y Turismo de Huaraz Ancash.

Superintendencia Nacional de Aduanas y de Administración Tributaria (SUNAT). (2012). Consulta RUC[ventana interactiva en línea] Fecha de consulta: 02/12/2011. Disponible en http://www.sunat.gob.pe/cl-ti-itmrconsruc/jcrS00Alias

Superintendencia Nacional de Aduanas y de Administración Tributaria (SUNAT). (2012). Consulta RUC[ventana interactivaen línea] Fecha de consulta: 05/12/2011. Disponible en http://www.sunat.gob.pe/cl-ti-itmrconsruc/jcrS00Alias

Texto Único Ordenado de la Ley de promoción de la competitividad, formalización y desarrollo de la MYPE y del acceso al empleo decente. Decreto Supremo N007-2008-TR, y su Reglamento aprobado por Decreto Supremo $N^{\circ} 0008-2008-T R$.

Weinberger Villarán, Karen. (2009). Estrategia para lograr y mantener la competitividad de la empresa. USAID - Ministerio de la Producción, Lima. 